\title{
Influence of species, age and diet on mercury concentrations in Shetland seabirds
}

\author{
F. M. Stewart, R. A. Phillips*, P. Catry, R. W. Furness \\ Applied Ornithology Unit, IBLS, University of Glasgow, Glasgow G12 8QQ, United Kingdom
}

\begin{abstract}
Chick down, chick feathers and feathers from adults of 5 seabird species (Arctic skua Stercorarius parasiticus, great skua Catharacta skua, Arctic tern Sterna paradisaea, kittiwake Rissa tridactyla, and common guillemot Uria aalge) were analysed for mercury. Individual female Arctic and great skuas' body feather mercury concentrations correlated with concentrations in their chicks' down, but not feathers (Arctic skua: $r=0.64$; great skua: $r=0.66$ ). This demonstrated that mercury in chick down originated from the egg, and that mercury in the egg and in adult females' plumage could have the same dietary source. Inter-specific differences in mercury concentrations were found for all age classes sampled, and these could be explained partly in terms of dietary specialisation, although physiological variations may also be important. All 3 age classes of great skua showed a direct increase in mercury with increasing proportion of bird meat in the diet of individual parrs. In kittiwake, Arctic skua and great skua, adults had higher mercury concentrations than chicks and chick down had higher concentrations than chick feathers. However, in 2 species (Arctic terns and gullemots) chick down had higher concentratıons than adult feathers. Chick town could be sampled for mercury content as an alternative to using eggs in national biomonitoring schemes. Feathered chicks could be sampled to determine mercury avalability around the breeding colony between hatching and fledging.
\end{abstract}

KEY WORDS: Biomonitoring $\cdot$ Diet $\cdot$ Heavy metals Individual varıation $\cdot$ Mercury Seabirds

\section{INTRODUCTION}

Seabird tissues have been widely used as biomonitors of heavy metals in the marine environment. Significant temporal and geographical variations have been demonstrated, polluted environments have been identified and contamination patterns monitored (Becker 1989, Walsh 1990, Thompson et al. 1992, Becker et al. 1993a, b)

Feathers are often used in such analyses, and as monitoring units they have several unique advantages. A sample of body feathers provides a consistent and reliable measure of the total mercury burden of the bird (Furness et al. 1986), sampling is relatively straightforward and non-invasive, and there is a wealth of material in museums which can be used for

\footnotetext{
- Present address: Dept of Biological Sciences, University of Durham, Durham DH1 3LE, United Kingdom.

E-mail:r.a.phıllıps@durharn.ac.uk
}

temporal studies and geographical comparisons (Walsh 1990, Thompson et al. 1992). However, when interpreting data on mercury concentrations in feathers, several factors must be considered. Birds are complex organisms and physiological and environmental factors will affect mercury burdens.

Two major determinants influencing mercury concentrations in seabirds are diet and age. Inter-specific differences in mercury burdens are often attributed to variations in diet or trophic level (Hutton 1981, Ohlendorf \& Harrison 1986, Braune 1987, Becker et al. 1994, Wenzel \& Gabrielsen 1995), but studies attempting to quantify this are lacking. Age has no effect on mercury concentrations in feathers once birds are fully grown (Furness et al. 1990, Thompson et al. 1991, Burger et al. 1994); mercury accumulated in internal tissues since the end of the previous moult cycle is excreted into the new plumage and thus gives a measure of mercury accumulated in the inter-moult period (Furness et al. 1986). By contrast, mercury concentrations in the 
plumage of chicks and immature birds may be gradually incorporated into down and feather during growth. The mercury concentrations in chick down are thought to reflect concentrations in the egg (Becker \& Sperveslage 1989, Becker et al. 1993a), but there are very few studies which have demonstrated a relationship between mercury concentrations of breeding females and that of the egg they produce (Lewis et al. 1993, Burger \& Gochfeld 1996).

Most studies have found that mercury concentrations in adults were higher than in chicks or sub-adults (Furness et al. 1990, Thompson et al. 1991, Monteiro et al. 1994, Stewart et al. 1994, Wenzel \& Gabrielson 1.995). However work on common terns Sterna hirundo has demonstrated higher concentrations of mercury in feathers (Monteiro \& Furness 1995) and very similar concentrations in the liver and feathers of chicks compared to adults (Gochfeld \& Burger 1987, Burger et al. 1994)

Studies which have investigated the age-related variation within chicks have come to apparently contradictory conclusions. Mercury concentrations in chick feathers showed increases with age in eastern great white egrets Egretta alba modesta and common terns (Honda et al. 1986, Becker et al. 1993a), but were independent of age in great skuas Catharacta skua (Thompson et al. 1991j and negatively correlated with age in several species from the Azores (Monteiro et al. 1994).

Analysis of the plumage of chicks can be more informative than that of adults in some circumstances, and many researchers have advocated chicks as useful long-term biomonitors (Walsh 1990, Furness 1993, Monteiro \& Furness 1995). Chicks accumulate mercury over a short period and can therefore provide information on bioavailability of metals from a localised foraging area and over a specific time period (from hatching to fledging). This however can be complicated by the residual mercury component in chicks derived from the adult female via the egg, which may be excreted into chick down (Becker et al. 1993a). This bias could be minimised by choosing chick feathers rather than down for analysis, depending on the requirements of the monitoring programme.

This study compares mercury concentrations in feathers of adults and chicks (downy and feathered young) of 5 species of seabird from Shetland, UK (common guillemot Uria aalge, Arctic tern Sterna paradisaea, Arctic skua Stercorarius parasiticus, kittiwake Rissa tridactyla, and great skua), to investigate the effects of species, age and diet on mercury concentrations. Individually marked Arctic skuas and great skuas were sampled to look at the relationship between mercury concentrations of individual adults and those of their chicks. Chicks of all species were sampled at different ages to determine mercury dynamics as the plumage changes from down to feathers. Finally, we look at intra-specific variation in individual mercury burdens in relation to diet of great skuas.

\section{MATERIALS AND METHODS}

Sample collection. Fieldwork took place in JuneJuly 1994 on. Foula $\left(60^{\circ} 08^{\prime} \mathrm{N}, 2^{\circ} 05^{\prime} \mathrm{W}\right)$, a small island approximately $22 \mathrm{~km}$ west of Shetland mainland.

Feathers were taken from samples of adults of 3 species (common guillemot, Arctic tern and kittiwake). down and feathers from Arctic tern and kittiwake chicks, and down only from guillemot chicks during the routine yearly ringing programme. Six to ten body feathers were removed from each adult and feathered chick and stored in polythene bags. Samples of down were plucked from the flank area of each chick. All birds were ringed, weighed and measured (maximum wing chord).

Adult Arctic skuas and great skuas were nesttrapped during incubation using a clap net, and feather samples taken as above. Arctic skua and great skua nests were marked and breeding performance was monitored for other ecological studies. Great skuas were sexed by observation. Arctic skuas were sexed by observation, by discriminant analyses where the probabilities of group membership were $>0.85$, or by association with a partner sexed by one of these methods (Phillips \& Furness in press). Chicks from marked nests were sampled twice, first as downy chicks and again when their feathers had grown. Not all great skua chicks were sampled a second time as several disappeared due to predation and fieldwork ended before some were old enough to have grown feathers.

The diets of great skua adults were determined by weekly collection and analysis of regurgitated pellets from marked territories. These contain the indigestible components of prey items such as fish otoliths, feathers, mammalian fur, goose barnacle Lepas sp. plates etc. Pellets are considered to be representative of prey taken by the adults, and indicative of food fed to chicks at the nest (Furness \& Hislop 1981). The proportion of all pellets sampled that consisted partly or wholly of feathers was calculated in order to determine the relative importance of bird flesh in the diet of individual pairs. For every territory marked and monitored for diet, at least downy chicks were sampled for mercury concentrations.

Chick ages. Chick ages were calculated from wing length for common guillemots (Harris et al 1991) and Arctic terns (Ewins 1985), and from body mass for kittiwakes (Galbraith 1983). Chick ages for Arctic and 
great skuas were calculated from observed hatching date.

Mercury analysis. Total mercury concentrations were determined by a cold vapour technique using a Data Acquisition Ltd DA 1500-DP6 Mercury Vapour Detector, preceded by a standard acid digestion (Furness et al. 1986). Feathers were dried to ambient laboratory temperature (ca $22^{\circ} \mathrm{C}$ ) before analysis. The reproducibility and accuracy of the mercury determination technique were tested by analysing International Atomic Energy Agency Horse Kidney Reference Material H-8 (Thompson \& Furness 1989). All mercury concentrations are expressed as $\mu \mathrm{g} \mathrm{g}^{-1}$ on a dry weight basis.

Statistical analysis. All statistical analyses were carried out using the SPSS-PC+ package (Norusis 1986 , 1988) and Zar (1984).

\section{RESULTS}

Mercury concentrations for all species and age classes are shown in Table 1 In general, adults showed a greater variation in mercury concentrations than either feathered chicks or downy chicks, as shown by their higher coefficients of variation. The exception to this is the Arctic tern where downy chicks showed slightly greater inter-individual variation compared to adults.

\section{Chick age and mercury concentrations}

Analysis of the effects of age on mercury concentrations were performed separately for downy and feathered chicks. Mercury concentrations were negatively correlated with chick age in guillemot down $(r=-0.42$, $\mathrm{p}=0.023, \mathrm{n}=29)$, and in kittiwake down $(\mathrm{r}=-0.60, \mathrm{p}=$ $0.040, n=12)$, and feather $(r=-0.45, p=0.020, n=26)$. There were no significant relationships with age in Arctic skua chick down $(r=-0.25, p=0.134, n=36)$ or feather $(r=0.14, p=0.451, n=30)$, nor in Arctic tern down $(r=0.04, p=0.858, n=24)$ or feather $(r=0.32, p=$ $0.246, n=15$ ). Similarly, mercury concentrations in great skua chicks did not show significant relationships with age in down ( $\mathrm{r}=-0.06, \mathrm{p}=0.624, \mathrm{n}=58$ ), although there was a negative, but just non-significant, trend in feather ( $r=-0.35, p=0.066, n=28$ ).

\section{Inter-specific differences}

Inter-specific differences in mercury concentrations were found in all age classes. There were significant differences in mercury concentrations between adults of the 5 seabird species (Kruskal-Wallis ANOVA, $\chi^{2}=$ $118.05, \mathrm{p}<0.0001, \mathrm{n}=160$ ). Non-parametric ranges test (Zar 1984) indicated that the great skua adults had significantly higher concentrations than all other species, kittiwake adults had significantly higher concentrations than both Arctic terns and guillemots, but not Arctic skuas, and Arctic skuas had higher concentrations than Arctic terns and guillemots. There was no difference between the last 2 species (Fig. 1).

Inter-specific comparison of mercury concentrations in feathered chicks showed a different pattern. There were differences in mercury concentrations between the species (Kruskal-Wallis ANOVA, $\chi^{2}=68.22$, $p<$ $0.0001, n=99$ ). Non-parametric ranges tests showed that great skua concentrations were significantly higher than all others and Arctic tern chicks had

Table 1 Mercury concentrations ( $\left.\mu \mathrm{g} \mathrm{g}^{-1}\right)$ in body feathers of adults and feathers and down of chicks. SD: standard deviation, $\mathrm{SE}$ : standard error, CV: coefficient of variation

\begin{tabular}{|c|c|c|c|c|c|}
\hline Species & Age class & Mercury mean $(n)$ & SD & SE & $\mathrm{CV}$ \\
\hline Guillemot & Adults & $0.99(34)$ & 0.34 & 0.059 & 34 \\
\hline Uria alalge & Downy chicks & $1.24(29)$ & 0.27 & 0.051 & 22 \\
\hline Kittiwake & Adults & $3.31(21)$ & 1.21 & 0.26 & 36 \\
\hline \multirow[t]{2}{*}{ Rissa tridactyla } & Downy chicks & $1.43(12)$ & 0.38 & 0.11 & 26 \\
\hline & Feathered chicks & $0.37(26)$ & 0.12 & 0.02 & 32 \\
\hline Arctic tern & Adults & $0.86(23)$ & 0.23 & 0.05 & 27 \\
\hline \multirow{2}{*}{ Sterna paradisaea } & Downy chicks & $2.03(24)$ & 0.66 & 0.13 & 32 \\
\hline & Feathered chicks & $0.69(15)$ & 0.14 & 0.04 & 20 \\
\hline Arctic skua & Adults & $2.52(28)$ & 2.23 & 0.42 & 88 \\
\hline \multirow[t]{2}{*}{ Stercorarlus parasilicus } & Downy chicks & $2.00(36)$ & 0.91 & 0.15 & 45 \\
\hline & Feathered chicks & $0.46(30)$ & 0.22 & 0.40 & 47 \\
\hline Great skua & Adults & $6.34(54)$ & 2.60 & 0.35 & 41 \\
\hline \multirow{2}{*}{ Catharacta skua } & Downy chicks & $4.15(58)$ & 1.39 & 0.18 & 34 \\
\hline & Feathered chicks & $1.22(28)$ & 0.38 & 0.07 & 31 \\
\hline
\end{tabular}




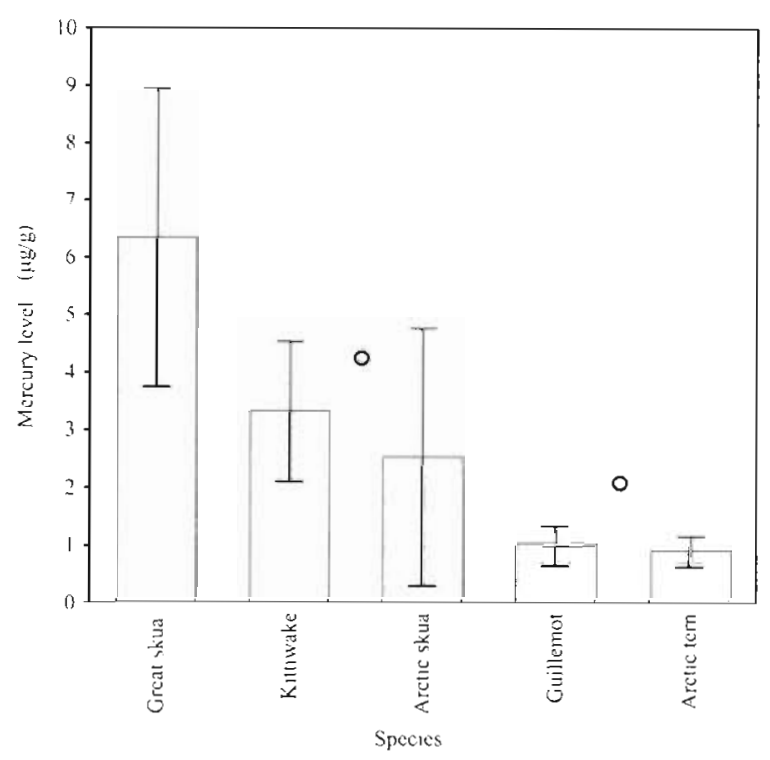

Fig. 1 Inter-specific differences in adult feather mercury levels for 5 species of seabird. Error bars are SD. (0) Species between which there were no differences in mercury levels All other differences were significant

higher concentrations than kittiwakes and Arctic skuas. There were no differences between kittiwakes and Arctic skua chick feather concentrations (Fig. 2).

Mercury concentrations in downy chicks also showed significant inter-specific differences (KruskalWallis ANOVA, $\chi^{2}=114.88, p<0.0001, n=159$ ). Great skua chicks had higher concentrations than all other

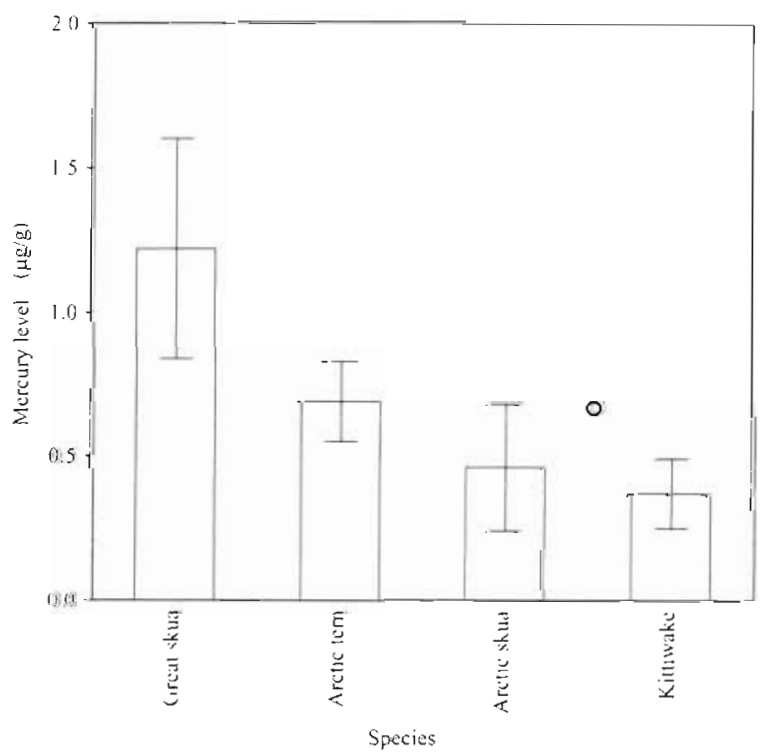

Fig. 2. Inter-specific differences in chick feather mercury levels for 4 species of seabird. Error bars are SD. (0) Species between which there were no differences in mercury levels. All other differences were significant species. There were no differences between Arctic terns, Arctic skuas and kittiwakes, but both Arctic terns and Arctic skuas had higher concentrations than guillemots. There were no differences between guillemots and kittiwakes (Fig. 3).

\section{Intra-specific age class differences}

All species showed significant differences in the pattern of variation between age classes in mercury concentrations. Guillemot chicks had significantly higher mercury concentrations than adults ( $t$-test, $t=-3.04$, $\mathrm{df}=61, \mathrm{p}=0.004)$.

There were significant differences between mercury concentrations with age class in kittiwakes (KruskallWallis ANOVA, $\chi^{2}=48.26, \mathrm{p}<0.0001, \mathrm{n}=59$ ). There were no differences between adult feather and chick down concentrations, but both were higher than chick feather concentrations.

In Arctic terns there were significant differences in mercury concentrations between the age classes (Kruskall-Wallis ANOVA, $\chi^{2}=44.70, p<0.0001, n=$ $62)$. There were no differences between adults and feathered chicks, but downy chicks had higher concentrations than either of these groups.

For Arctic skuas, again there were age class differences (Kruskall-Wallis ANOVA, $\chi^{2}=57.61, p<0.0001$, $\mathrm{n}=94$ ). There was no difference between concentrations in adult and downy chicks, although both were higher than in feathered chicks.

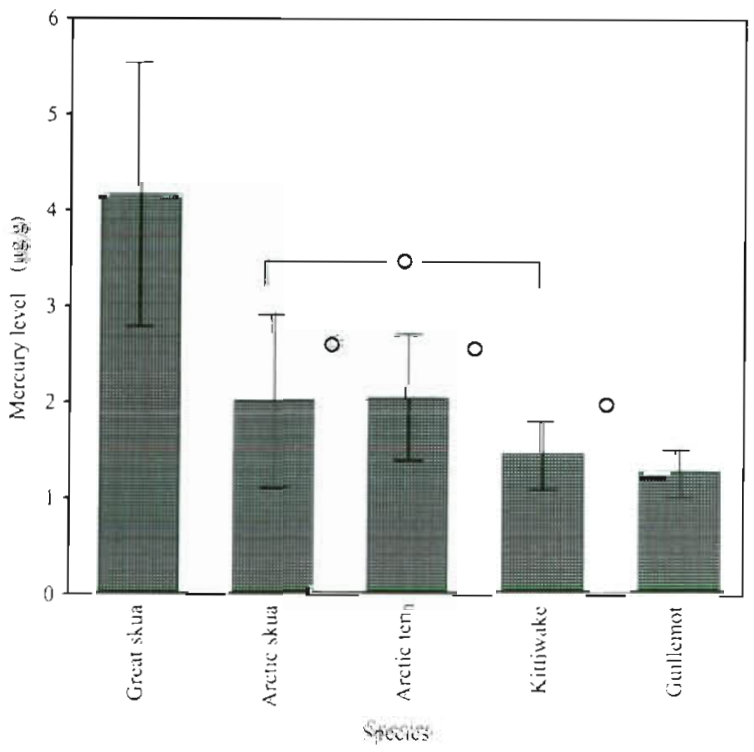

Fig. 3 Inter-specific differences in chick down mercury levels for 5 species of seabird. Error bars are SD. (O) Species between which there were no differences in mercury levels. All other differences were significant 
For great skuas there were differences between age classes (Kruskall-Wallis ANOVA, $\chi^{2}=83.16, p<$ $0.0001, n=140$ ). Adults had higher concentrations than either chick age class, and chick down concentrations were higher than chick feather concentrations.

\section{Comparison between individuals and their broods in Arctic skuas and great skuas}

A clear relationship was found between adults and their chicks in both Arctic and great skuas. The concentrations of mercury in the adult females' body feathers correlated with their chicks' down (Arctic skua: $r=0.64, n=20, p=0.002$; great skua: $r=0.66, p=$ $0.002, n=20$ ) but not feather mercury concentrations (Arctic skua: $r=0.13, p=0.599, n=19$; great skua: $r=$ $0.23, p=0.492, n=11$ ), whereas the mercury concentrations in the male birds did not show any relationship with chick down (Arctic skua: $\mathrm{r}=-0.05, \mathrm{p}=0.837, \mathrm{n}=$ 16; great skua: $r=-0.080, p=0.816, n=11$ ) or feather (Arctic skua: $\mathrm{r}=0.36, \mathrm{p}=0.249, \mathrm{n}=12$; great skua: $\mathrm{r}=$ $0.74, \mathrm{p}=0.156, \mathrm{n}=5$ ).

Paired comparisons indicate that individual chicks had significantly higher concentrations of mercury in down than in their feathers in both Arctic skuas (paired sample $t$-test, $t=12.91, \mathrm{df}=28, \mathrm{p}<0.001$ ) and great skuas (paired sample $t$-test, $t=9.89, \mathrm{df}=17, \mathrm{p}<0.001$ ). However, there were no correlations between mercury concentrations in down and feathers of individual Arctic skua ( $\mathrm{r}=0.237, \mathrm{p}=0.217, \mathrm{n}=29$ ), or great skua chicks $(r=0.20, p=0.428, n=18)$.

Mercury concentrations in Arctic skua chicks from the same brood were correlated in down $(r=0.58, p=$ $0.04, n=12)$, but not in feather $(r=-0.06, p=0.85, n=$ 11). Great skuas showed a similar pattern: mercury concentrations in chicks from the same brood were correlated for down $(\mathrm{r}=0.82, \mathrm{p}=0.013, \mathrm{n}=8)$. There was not a large enough sample to test this for concentration in chick feathers

\section{Diet and mercury concentrations}

The proportion of bird flesh in great skua diet (as indicated by pellet analysis) showed considerable variation, with some pairs apparently feeding entirely on discarded gadid fish obtained from demersal fisheries, in contrast to others which appeared to consume only bird flesh. The dietary data were converted to the proportion of all pellets that contained feathers, and data were arcsine transformed. Great skua mercury concentrations in plumage were significantly and positively correlated with the proportion of bird meat in the diet for adult feathers $(r=0.37, p<0.02, n=40)$, chick feathers $(\mathrm{r}=0.75, \mathrm{p}<0.001, \mathrm{n}=20)$ and chick down $(r=0.36, p<0.01, n=56)$.

\section{DISCUSSION}

\section{Adults and their chicks}

Mercury concentrations in the down of chicks is thought to originate from the egg, with mercury being transported into the down during embryonic development. Becker \& Sperveslage (1989) found that concentrations of mercury in eggs and $5 \mathrm{~d}$ old downy chicks of herring gull Larus argentatus from the same clutch were strongly correlated, and concluded that the mercury found in chick down was due mainly to the concentrations in the egg.

Mercury concentrations in eggs are thought to reflect local contamination of mercury in food items ingested in the period just prior to egg-laying (Barrett et al. 1985, Becker 1992, Becker et al. 1993b, Furness 1993, Lewis et al. 1993, Monteiro \& Furness 1995). Lewis et al. (1993) measured mercury concentrations in feathers, eggs and soft tissues of herring gulls. They found that mercury concentrations in eggs were not correlated with concentrations in feathers of individual females, although they were significantly related to the liver concentrations. The implication from these results was that mercury in feathers and in the liver did not have the same source; feather mercury would originate from food eaten during the moulting period plus the mercury stored in soft tissues between moults (Furness et al. 1986). Therefore, mercury concentrations in the eggs were thought to originate from mercury ingested immediately prior to egg-laying and thus reflect local contamination at the breeding site. Becker et al. (1993b) showed high inter-site variations in mercury levels in both eggs and chick feathers which indicated differences in local contamination. However, our results suggest that this may not always be the case. The significant positive relationship between mercury concentration in plumage of adult female great and Arctic skuas and the down of their chicks indicates a close relationship between mercury concentrations in the adult plumage and egg mercury concentrations. In addition, there was no correlation between mercury concentrations in the down of individual chicks and that in their feathers, which would be expected if mercury concentrations in each resulted from accumulation from prey caught close to the colony. As chick feather mercury concentrations were clearly much lower than down concentrations, it may be hypothesised that either mercury found in the egg is accumulated over a longer time period by the female prior to laying, adults accumulate more mercury than chicks due to higher 
food intakes (especially around laying), egg mercury does contain a portion of the female's body burden accumulated since the previous moult, or that individual females have year-round dietary preferences which consistently influence mercury inputs into eggs and plumage. If it were true that adults accumulate more mercury than chicks because of a higher food intake within a short time period, then one would still not expect a correlation between adult plumage and chick down concentrations, as is seen here. The fact that we have also found a relationship between summer diet and mercury levels in feathers of great skuas is also important. Levels of mercury in body feathers are thought to reflect year-round accumulation, but it may be that summer diet has a greater influence on mercury levels in feathers than previously realised. A positive correlation was also found between mercury levels in body feathers of females and eggs of Franklin's gull Larus pipixran (Burger \& Gochfeld 1996) This species returns to the colony only a few days before egg-laying and therefore the source of mercury must originate from outside the breeding area.

\section{Age-related trends}

Kittiwakes, Arctic skuas and great skuas demonstrated similar age-related trends in mercury concentrations; adults had a higher concentration in their feathers than was found in chick down (although the difference was only significant in great skuas), which was in turn greater than levels in chick feathers. Adults would be expected to have accumulated greater concentrations because of a long exposure time to dietary mercury since the previous moult (Furness et al. 1990, Thompson et al. 1991, Monteiro et al. 1994, Wenzel \& Gabrielson 1995). Chick down concentrations were higher than chick feather concentrations as mercury in down originates from the adult female via the egg (see previous section). Chick feather concentrations reflect the amount of mercury accumulated from around the colony (and hence circulating in the blood at the time of feather formation) during the period from hatching to feather growth (Furness et al. 1986, Braune \& Gaskin 1987. Walsh 1990).

The reduction in mercury concentrations with increasing chick age in guillemots and kittiwakes (within the downy or feathered chick age categories) is most likely due to a dilution effect. Young chicks have a high rate of protein synthesis, presumably resulting in mercury dilution in the tissues during the phase of rapid growth (Thompson et al. 1991, Monteiro et al. 1994).

Arctic term and guillemot chicks had significantly higher concentrations of mercury in their down than was found in adult feathers (in the case of terns more than double ${ }_{i}$ adult mean $=0.86 \mu \mathrm{g} \mathrm{g}^{-1}$, chick down mean $=2.03 \mu \mathrm{g} \mathrm{g}^{-1}$ ). This was also recorded in common terns breeding in the Azores where hatchlings had a mean of $4.8 \mu \mathrm{g} \mathrm{g}^{-1}$ mercury in their down compared with $2.5 \mu \mathrm{g} \mathrm{g}^{-1}$ in the feathers of adults (Monteiro \& Furness 1995). Both Arctic terns and guillemots undergo a partial pre-nuptial moult (Ginn \& Melville 1983) which would reduce the body burden of mercury. In the female, tissue mercury levels are further reduced by excretion into the eggs and consequently body feathers grown in the post-nuptial period will have lower levels related to this reduced body pool. Adult females may lower their body pool of mercury between moults by excreting a significant amount of what is a potentially toxic material into the egg (Braune \& Gaskin 1987, Becker 1993a, Lewis et al. 1993). Indeed, Lewis et al. (1993) estimated that in comparison with males, female herring gulls could potentially excrete over $20 \%$ more mercury via their eggs. Other studies on auks and gulls also found significantly lower mercury concentrations in feathers of females than males (Braune \& Gaskin 1987. Stewart et al. 1994).

\section{Inter-specific differences}

There were significant differences in mercury concentrations between species in all age classes. Such inter-specific variations will result from differences in diet, body size, moult strategy, migration patterns, physiology, or a combination of these (Walsh 1990 , Monteiro \& Furness 1995). Frequently diet is considered to be the most important factor (Hutton 1981. Ohlendorf \& Harrison 1986, Braune 1987, Becker et al. 1994. Wenzel \& Gabrielsen 1995). In this study mercury concentrations accumulated by feathered chicks were presumably dependent on food ingested between hatching and feather growth, and so we can relate the variations in mercury concentrations between species to differences in diets. The diet of great skua chicks is much more varied than that of the other species as it may consist of sandeels, bird meat, goose barnacles or discarded gadid fish obtained from trawlers, whereas the other species studied all feed almost exclusively on sandeels (Furness 1990, Bailey et al. 1991) The diet of great skuas would be expected to contain a higher mercury content as methylmercury shows bioamplification and many of their prey species are from higher trophic levels. Indeed, mercury concentrations in great skua chick feathers were clearly higher than in the other species (see Fig. 2). Kittiwake, Arctic tern and Arctic skua chicks are fed on approximately the same age class and size range of sandeels 
(Furness 1990, Bailey et al. 1991) and we may expect the mercury concentrations accumulated in their feathers to be roughly comparable, unless factors other than diet were involved. In fact, the pattern of mercury accumulation did not follow these expectations (see Fig. 2) and therefore it must be concluded that physiological differences do play an important role. In particular it seems that terns have an unusual and distinct pattern of mercury accumulation (Gochfeld \& Burger 1987, Burger et al. 1994, Monteiro \& Furness 1995, this study). Therefore, this suggests that invoking dietary differences to be the principle factor influencing interspecific variation in metal concentrations in chicks may in many cases be overly simplistic, and other sources of variation must be considered (Walsh 1990, Monteiro et al. 1994). Likewise any explanation of interspecific differences in adult feather levels (Fig. 3) would require a detailed analysis of all the factors involved. Future work should investigate the influence of these other factors which contribute to patterns of heavy metal accumulation.

\section{Intra-specific variation in diet}

Variation in mercury concentrations within a species can be more readily attributed to dietary variation. The relative proportion of bird meat in the diet of great skuas from individual territories was positively correlated with the mercury burden of adults, and both chick down and chick feather concentrations. Such a clear relationship between diet and mercury levels has never been demonstrated previously in a single freeliving species. In an earlier study, Thompson et al. (1991) also investigated the diet of great skuas using pellet analysis, but found no relationship with plumage mercury concentrations in adults, hence they concluded that winter diet must be more important in determining the mercury burden. However, their study was undertaken in a year when there were few sandeels available, and consequently the range of prey items in the diet would have been more limited. In addition, there had been a recent switch to increased predation on bird flesh in the absence of sandeels (Hamer et al. 1991) and adults may have been feeding on quite different prey in the previous year. This would serve to uncouple the relationship between diet and adult mercury concentrations as a change in mercury intake would not be apparent in mercury burdens of plumage until the following year

It is clear from the data that the relationship between diet and mercury concentrations explains most variation in chick feathers $\left(r^{2}=0.56\right)$, and much less variation in both chick down $\left(\mathrm{r}^{2}=0.13\right)$ and adult feather mercury concentrations $\left(\mathrm{r}^{2}=0.14\right)$. This would be expected as the latter 2 also reflect dietary mercury uptake outside of the short breeding season (see previous section). These relationships indicate firstly that dietary variation has a direct and measurable effect on mercury concentrations within a species, and secondly that chick feather concentrations are the most appropriate indicator of the bioavailability of mercury during the breeding season

\section{Implications for biomonitoring}

Eggs have been used successfully as a monitoring tissue to investigate geographical variation in mercury and organochlorine concentrations (Walsh 1990), and indeed are collected as part of several national biomonitoring schemes (Furness 1993). However, as these results show, sampling down or feathers from young chicks in order to monitor mercury levels would be equally appropriate and would have several obvious advantages. Chicks could be sampled easily without killing them, sample sizes could be much larger, and it also would eliminate either brood reduction or the energetic cost to the female of laying a replacement egg. Additionally, down and feather samples are easier to store for future analysis, as eggs have to be kept frozen. The problem still remains that we do not know whether egg and down concentrations are an adequate reflection of local environmental contamination. As our findings suggest, this may not always be the case and further work is necessary to clarify the situation.

This study has shown that chick feathers could be sampled to measure the bioavailability of mercury to birds in the period from hatching to fledging, although inter-specific differences should be considered. Our results indicate that chick feathers could be an excellent indicator of mercury availability around seabird colonies particularly if coupled with dietary data. This could be useful for ongoing monitoring or geographical studies, especially in inshore areas most likely to be affected by pollution (Walsh 1990). Interspecific differences in physiology are important though and should be investigated. The relationship between diet and mercury burdens in the plumage of adult birds may be less straightforward because of time spent away from the breeding colony during the majority of the year.

Acknowledgements. This research was supported by a Carnegie Trust small project grant, SOTEAG, The Nuffield Foundation and the Natural Environment Research Council. P.C. was funded by Junta Nacional de Investigação Cientifica e Tecnológica (Grant BD/2556/93). Thanks to Dr B. Calvo for help with the collection of feathers, and Dr D. R. Thompson for helpful comments on the manuscript. 


\section{LITERATURE CITED}

Bailey RS, Furness RW, Gauld JA, Kunzlik PA (1991) Recent changes in the population of the sandeel (Ammodytes marinus Raitt) at Shetland in relation to estimates of seabird predation. ICES Mar Sci Symp 193:209-216

Barrett RT, Skarre JU, Norheim G, Vader W, Froslie A (1985) Persistant organochlorines and mercury in eggs of Norwegian seabirds 1983. Environ Pollut (A) 39:79-93

Becker PH (1989) Seabirds as monitor organisms of contaminants along the German North Sea coast. Helgol Meeresunters 43:395-403

Becker PH (1992) Egg mercury levels decline with the laying sequence in Charadriiformes. Bull Environ Contam Toxi$\mathrm{Col} 48: 762-767$

Becker PH, Furness RW, Henning D (1993a) Mercury dynamics in young common tern (Sterna hirundo) chicks from a polluted environment. Ecotoxicology 2:33-40

Becker PH, Furness RW, Henning D (1993b) The values of chick feathers to assess spatial and interspecific variation in the mercury contamination of seabirds. Environ Monit Assess 28:255-262

Becker PH, Henning D. Furness RW (1994) Differences in mercury contamination and elimination during feather development in gull and tern broods. Arch Environ Contam Toxicol 27:162-167

Becker PH, Sperveslage H (1989) Organochlorines and heavy metals in herring gull (Larus argentatus) eggs and chicks from the same clutch. Bull Environ Contam Toxicol 42: $721-727$

Braune BM (1987) Comparison of total mercury levels in relation to diet and molt for nine species of marine birds. Arch Environ Contam Toxicol 16:217-224

Braune BM, Gaskin DE (1987) Mercury levels in Bonaparte's gulls Larus philadelpha durng autumn molt in the Quoddy Region, New Brunswick. Canada. Arch Environ Contam Toxicol 16:539-549

Burger J, Gochfeld M (1996) Heavy metal and selenium levels in Franklin's gull (Larus pipixcan) parents and their eggs Arch Environ Contam Toxicol 30:487-491

Burger J, Nisbet ICT, Gochfeld M (1994) Heavy metals and selenium levels in feathers of known-aged common terns (Sterna hirundo). Arch Eriviron Contam Toxicol 26 $351-355$

Ewins PJ (1985) Growth, diet and mortality of Arctic tern Sterna paradisaea chicks in Shetland. Seabird 8:59-68

Furness RW (1990) A preliminary assessement of the quantities of Shetland sandeels taken by seabirds, seals, predatory fish and the industrial fishery in 1981-1983. Ibis 132 $205-217$

Furness RW (1993) Birds as monitors of pollutants. In: Furness RW, Greenwood JJD (eds) Birds as monitors of environmental change. Chapman \& Hall, London, p 86-143

Furness RW, Hislop JRB (1981) Diets and feeding ecology of great skuas Catharacta skua during the breeding season in Shetland. J Zool Lond 195:1-23

Furness RW, Lewis SA, Mills JA (1990) Mercury in the plumage of red-billed gulls Larus novaehollandiae of known sex and age. Environ Pollut 63:33-39

Furness RW, Muirhead SJ, Woodburn M (1986) Using bird feathers to measure mercury in the environment: relationships between mercury content and moult. Mar Pollut Bull $17: 27-30$

Galbraith H (1983) The diet and feeding ecology of breeding kittiwakes Rissa tridactyla. Bird Study 30:109-120

Ginn HB, Melville DS (1993) Moult in birds. BTO guide no. 19. British Trust for Ornithology, Tring

Gochfeld M. Burger J (1987) Factors affecting tissue distribution of heavy metals. Age effects and metals concentration patterns in Common terns, Sterna hirundo. Biol Trace Elem Res 12:389-399

Hamer KC, Furness RW, Caldow RWG (1991) The effects of changes in food availability on the breeding ecology of great skuas Catharacta skua in Shetland. J Zool Lond 223: $175-188$

Harris MP, Halley DJ, Wanless S (1991) The post-fledging survival of young guillemots Uria aalge in relation to hatching date and growth. Ibis 134:335-339

Honda K, Min BY, Tatsukawa R (1986) Distribution of heavy metals and their age related changes in the eastern great white egret Egretta alba modesta, in Kored. Arch Environ Contam Toxicol 15:185-187

Hutton M (1981) Accumulation of heavy metals and selenium in three seabird species from the United Kingdom. Environ Pollut (A) 26:129-145

Lewis SA, Becker PH, Furness RW (1993) Mercury levels in eggs, tissues and feathers of herring gulls Larus argentatus from the German Wadden sea coast. Environ Pollut 80: 293-299

Monteiro LR, Furness RW (1995) Seabirds as monitors of mercury in the marine environment. Water Air Soil Pollut 80: $851-870$

Monteiro LR, Furness RW, del Nevo AJ (1994) Mercury levels in seabirds from the Azores, Mid-North Atlantic ocean. Arch Environ Contam Toxicol 28:304-309

Norusis MJ (1986) SPSS/PC+. SPSS Inc, Chicago

Norusis MJ (1988) SPSS/PC+ advanced statistics, version 2.0. SPSS Inc, Chicago

Ohlendorf HM, Harrison CS (1986) Mercury, selenium, cadmium and organochlorines in eggs of three Hawaiian seabird species. Environ Pollut (B) 11:169-191

Phillips RA, Furness RW (in press) Predicting the sex of parasitic jaegers by discriminant analysis. Colon Waterbirds

Stewart FM, Thompson DR, Furness RW, Harrison N (1994] Seasonal variation in heavy metal levels in tissues of common guillemots, Uria aalge from Northwest Scotland. Arch Environ Contam Toxicol 27:168-175

Thompson DR, Furness RW (1989) Comparison of total and organic mercury in seabird feathers. Mar Pollut Bull 20: $577-579$

Thompson DR, Furness RW, Walsh PM (1992) Historical changes in mercury concentrations in the marine ecosystem of the north and north-east Atlantic ocean as indicated by seabird feathers. J Appl Ecol 29:79-84

Thompson DR, Hamer KH, Furness RW (1991) Mercury accumulation in great skuas Catharacta skua, of known age and sex, and its effects upon breeding and survival. $J \mathrm{Appl}$ Ecol 28:672-684

Walsh P (1990) The use of seabirds as monitors of heavy metals in the marine environment. In: Furness RW, Rainbow PS (eds) Heavy metals in the marine environment. CRC Press, Boca Raton, FL, p 183-204

Wenzel C, Gabrielsen GW (1995) Trace element accumulation in three seabird species from Hornøya, Norway. Arch. Environ Contam Toxicol 29:198-206

Zar JH (1984) Biostatistical analysis, 2nd edn. Prentice-Hall Inc, Englewood Cliffs, NJ

Manuscript first received: July 25, 1996

Revised version accepted: January 7, 1997 